\title{
What's Happened at Divested Bank Offices? An Analysis of Antitrust Divestitures in Bank Mergers in the U.S.
}

\author{
Steven J. Pilloff* \\ Hood College, U.S.A.
}

In their competitive analysis of proposed bank mergers, the Board of Governors of the Federal Reserve System, the U.S. Department of Justice, and other U.S. banking agencies accept branch divestitures as an antitrust remedy in local markets where there is substantial overlap between the acquirer and target. The results of this study, which examines the performance of 751 branches that were divested between June 1989 and June 1999 in conjunction with a merger in the U.S. that raised possible competition issues, are consistent with the policy of accepting branch divestitures as an antitrust remedy being successful. Divested branches operate for lengths of time that are comparable to all branches, and even though they experience substantial deposit runoff around the time of the merger, divested branches subsequently exhibit deposit growth rates that are comparable to those of other similar branches (JEL: L40, G21, G34).

Keywords: divestiture, bank merger, antitrust policy and remedy, competition.

\section{Introduction}

Over the past two decades, the U.S. banking industry has experienced an unprecedented level of consolidation. Merger activity has been particularly intense over the latter half of this period. For example, more than 4,400 bank mergers, involving the acquisition of almost $\$ 2.9$

\footnotetext{
* I would like to thank Dean Amel, Robin Prager, Darrel Cohen, and attendees of a seminar sponsored by the Financial Institutions Committee of the Antitrust Section of the American Bar Association for helpful comments and Charles Taragin for excellent research assistance. I am also extremely grateful to Rich Gebert of the U.S. Department of Justice for providing me with valuable information on the identity of divested offices. Anonymous referee comments are also greatly appreciated. The views expressed in this paper are the author's and do not reflect those of the Board of Governors of the Federal Reserve System or its staff.
}

(Multinational Finance Journal, 2005, vol. 9, no. 1 \& 2, pp. 43-71)

(C) Multinational Finance Society, a nonprofit corporation. All rights reserved. DOI: $10.17578 / 9-1 / 2-3$ 
trillion in total deposits, took place between 1990 and 2001. This immense consolidation substantially changed the structure of the U.S. banking industry. ${ }^{1}$ For example, between 1990 and 2001, the number of commercial banking organizations operating in the U.S. decreased by nearly 30 percent to roughly 6,600 , and the share of assets and deposits controlled by the largest banks increased substantially. The 25 largest commercial banking organizations held 35 percent of domestic deposits in 1990 , but by 2001, that figure had grown to 55 percent. $^{2}$

Even though banking has undergone large structural changes at a nationwide level, structural measures at the local level suggest that a substantial decline in competition has probably not taken place. Antitrust authorities in the U.S. have defined retail-banking markets to be local in nature. Many studies of bank performance use the local area as the relevant geographic market definition, and results from these studies are frequently consistent with banking markets being local. ${ }^{3}$ In addition, recent versions of the Federal Reserve Board's Survey of Consumer Finances (1998) and Survey of Small Business Finances (1998) indicate that households and small businesses continue to rely heavily on local financial institutions, especially commercial banks. ${ }^{4}$ Offices of commercial banks and savings institutions, or thrifts, have remained important, increasing in number from about 84,000 in 1990 to roughly 87,000 in $2001 .^{5}$

Between June 1990 and June 2001, the average HerfindahlHirschman index (HHI), based on commercial banking deposits, decreased in both metropolitan statistical areas (MSAs) and non-MSA

1. Throughout this paper, unless noted otherwise, the U.S. banking industry refers to both commercial banks and savings institutions (savings and loan associations and savings banks). In addition, the terms merger and acquisition are used interchangeably, and the term branch is used to refer to any deposit-taking office of a commercial bank or savings institution.

2. Merger data were obtained from the SNL Financial Bank Mergers and Acquisitions database. Concentration data are as of year-end and were obtained from the National Information Center and Reports of Condition and Income.

3. For example, see Pilloff and Rhoades (2002), Pilloff (1999), Berger and Hannan (1998), Hannan and Prager (1998), Hannan (1997), Kamerschen and Frame (1997), Hannan and Liang (1995), and Rhoades (1995).

4. See Amel and Starr-McCluer (2002).

5. Data on the number of offices at FDIC-insured commercial banks and savings institutions are as of year-end and were obtained from the FDIC. 
counties. ${ }^{6}$ When the deposits of thrifts are included in calculations at 50 percent, which is consistent with the approach typically taken by the Federal Reserve Board (FRB) in its competitive analysis of bank mergers, the data continue to suggest that competition has not been substantially reduced in the U.S. The average HHI in non-MSA counties declined slightly, and although the MSA average increased by 140 points, the average level in 2001 was roughly 1600, suggesting that concentration has remained moderate and, therefore, competition has been at least reasonably strong. ${ }^{7}$

The U.S. banking industry has experienced substantial consolidation, yet has not seen a large decline in competition at the local level, because many mergers have involved banks with operations in different geographic areas. These deals may have reduced the number of organizations in the country and may have raised concentration at the national level, but because they did not alter the structure of local markets, they did not likely reduce competition at the local level.

However, many other deals involved banks with geographic overlap. If certain of these transactions had been permitted to proceed without modification, the result would have been large increases in and high levels of concentration, and large market shares held by the consolidated firm. To avoid these anti-competitive structural effects, banks have divested branches. By divesting a relatively small number of branches in markets with extensive overlap, banks have been able to eliminate possible competitive problems raised by mergers and complete a substantial number of deals, including numerous large ones that have transformed the U.S. banking industry.

The basics of a branch divestiture are simple: within 180 days of the primary merger being consummated, one or more branches (and all associated deposits and loans) are sold to another financial institution that subsequently owns and operates those branches. Customers of the divested branch typically receive a letter in the mail explaining that the branch that holds their account has been purchased by another financial institution, and that they are now customers of that other bank or thrift. The level of deposits that are divested is sufficiently large that the

6. The deposit data used to compute concentration measures were obtained from the Summary of Deposits.

7. Under the Department of Justice Merger Guidelines, a market is considered unconcentrated if the $\mathrm{HHI}$ is under 1000, moderately concentrated if the $\mathrm{HHI}$ is between 1000 and 1800 , and highly concentrated if the $\mathrm{HHI}$ is more than 1800 . 
increase in and resulting level of concentration in the market and the post-merger market share of the consolidated organization are low enough to satisfy the concerns of U.S. antitrust authorities and bank regulators.

A critical element of divestitures being an effective tool for antitrust policy is that the firm that purchases a divested branch be able to operate it effectively. By retaining and attracting customers, a divested branch can remain a viable option for banking customers and can therefore exert a pro-competitive influence on the market. If divested branches do not retain and attract customers, then they are unlikely to provide a meaningful competitive presence, thereby leading to a lower level of competition in the market.

In this paper, the issue of how divested branches in the U.S. have performed is examined. The length of time that divested branches operate after being sold and changes in deposit levels are measured for a sample of 751 bank and thrift branches that were divested between June 1989 and June 1999.

Analysis indicates that the share of divested branches that operated for at least a certain number of years following divestiture is generally not substantially different from the share of other, similar branches in the U.S. that operated for a comparable length of time. Changes in the level of deposits held at divested branches, however, show a distinct pattern that differs from other branches. Divested branches lost almost 13 percent of their deposits in the period spanning the June immediately preceding the merger to the June following divestiture, which is significantly different from the positive median growth rate experienced among all branches and the negative, yet smaller in magnitude, growth rate of branches that were acquired, but not divested. After this initial "runoff period," divested branches exhibited deposit growth that was generally comparable to other branches.

The issue of whether divestitures have had a pro-competitive effect in markets affected by potentially anti-competitive mergers is important and timely. The U.S. Federal Trade Commission (FTC) and U.S. Department of Justice (DOJ) commonly rely on divestitures to remedy possible anti-competitive harm associated with proposed mergers in a variety of industries in the U.S. The importance of the issue is underscored by a recent report released by the U.S. General Accountability Office in September 2002 that specifically recommends that the FTC undertake a study to assess the effectiveness of recent 
divestitures in retail markets. ${ }^{8}$ In addition, extensive bank consolidation has recently taken place in many countries, and issues related to competition policy are widely relevant. ${ }^{9}$ The results based on the performance of divested bank branches presented in this paper make a valuable contribution to better understanding the issue of whether divestitures are an effective remedy for potentially anti-competitive mergers.

The paper is organized as follows: Section II presents related research on the topic. Section III provide a brief review of DOJ and FRB policies on bank divestitures. Section IV describes the data. Sections V and VI presents the survival rates and growth rates analyses. Section VII presents the conclusions.

\section{Related Research}

Although issues associated with the effectiveness of divestitures in bank merger policy are highly relevant, there has been little research conducted on the subject. Besides this paper, Burke (1998) is the only other examination of the post-divestiture performance of divested branches. ${ }^{10}$ However, the results of various other studies suggest that branch divestitures may be an effective antitrust remedy in banking.

Perhaps the most fundamental result comes from the numerous papers that have found a positive relationship between the $\mathrm{HHI}$ in a market and bank prices and profits. ${ }^{11}$ These findings suggest that the HHI is inversely related to the level of competition. Therefore, divestitures, which have the effect of reducing the post-merger HHI, should be pro-competitive. In addition, the number of competitors in a market has been found to be positively related to bank prices and

8. See United States General Accountability Office (2002).

9. Group of Ten (2001) provides a thorough review of bank merger and acquisition activity in thirteen of the largest economies in the world.

10. Burke (1998), which analyzes 210 branches that were divested in association with deals completed between 1985 and 1992, involves a much smaller sample and less rigorous analysis than this study. Burke's results are consistent with divestitures being a successful antitrust remedy.

11. For example, see Hannan and Prager (2003), Heitfield and Prager (2002), Pilloff and Rhoades (2002), Kahn, Pennacchi, and Sopranzetti (2000), Cyrnak and Hannan (1999), and Berger and Hannan (1989). 
profits, and entry has been found to reduce profits. ${ }^{12}$ For these reasons, a divestiture to a new entrant, which is often preferred by antitrust authorities, should promote post-merger competition by leaving the number of competitors in a market unchanged.

As noted, survey responses indicate that many households and small businesses choose to use a bank that is located nearby. The apparent importance placed on location suggests that many customers may continue using their traditional branch, despite an ownership change. Thus, a divested branch with an established customer base could provide the market with a source of meaningful competition.

\section{Divestiture Policy: DOJ and FRB Approaches}

An effective divestiture policy must incorporate several elements. First, the level of deposits and loans to be sold must be specified, in addition to identifying which deposits and loans are to be divested. The analysis in this paper does not directly address these elements of divestiture policy. A second, and not altogether unrelated, element is determining which branches should be sold. Characteristics that may be important include whether or not the branch originally belonged to the firm that survives the merger, the location of the branch, and the composition of the branch's asset and deposit portfolios. A third aspect of a divestiture policy is determining which firms can and should purchase branches. A key issue related to this aspect is whether one firm should purchase all of the divested branches in a market. Other key issues involve whether the purchaser should already have a presence in the market, be a bank or a thrift institution, or be of a certain size.

The Federal Reserve Board (FRB) and the U.S. Department of Justice (DOJ) are the two agencies in the U.S. most heavily involved in evaluating the competitive effects of proposed bank mergers and overseeing the divestiture of branches. The FRB must approve or deny all mergers in which the resulting firm would be a bank holding company or a state member bank. The DOJ has enforcement powers and can investigate and challenge any proposed bank merger that it chooses. To prevent the FRB from denying or the DOJ from blocking a proposed acquisition, bank acquirers frequently propose divestitures to reduce

12. For example, see Pilloff and Rhoades (2002) regarding the number of firms and Amel and Liang (1997) regarding entry. 
competitive concerns raised by a planned merger. Both agencies have divestiture policies whereby they require, or in some cases prefer, divestiture packages to exhibit certain characteristics.

The Department of Justice takes a very active role in the divestiture process. ${ }^{13}$ One of their main concerns is minimizing runoff at divested branches, which occurs when depositors at such offices close their accounts and move their funds elsewhere. Runoff can take place either before or after the actual divestiture takes place. The DOJ generally requires that divested branches belong to the firm that will not survive the merger, typically the target, so that depositors do not have the opportunity to reopen their accounts at another branch of their former institution. The DOJ will often accept a "clean-sweep" divestiture of acquirer branches in which all acquirer branches in a market are divested. However, the agency generally opposes divestiture packages that include both acquirer and target branches, because such packages typically involve facilities that operate under different accounting, computer, and other systems, making them especially difficult for a purchaser to integrate.

The Justice Department has several other requirements that are intended to minimize deposit runoff. Among them, they prohibit merging parties from taking steps that would encourage pre-divestiture deposit runoff, such as providing extremely poor customer service or offering highly uncompetitive rates. The acquirer from the primary merger is also prohibited from soliciting customers of branches that are being divested. In general, banks are prohibited from simply transferring customer accounts from a divested branch to a non-divested branch. ${ }^{14}$

The Justice Department also closely looks at the location and activity of divested branches. They prefer that branches be sold that provide the purchaser with good geographic coverage of an area. Because branch location is important to bank customers, good

13. The discussion of the divestiture policy of the Department of Justice is based largely on Neill (2001) and Kramer and Grace (2001), and the discussion of the divestiture policy of the Federal Reserve Board is based in part on Neill (2001) and Burke (1998). Some aspects of current divestiture policy may not be relevant for earlier portions of the sample period analyzed in this paper.

14. In some cases, with the agreement of the Department of Justice and the Federal Reserve Board, certain customer accounts that are affiliated with a divested branch are not included in the divestiture. These customers generally account for a small portion of a branch's total level of business activity and are withheld from the divestiture for a specific reason such as the deposits belonging to a senior executive of one of the merging parties. 
geographic coverage enables banks to appeal to a large portion of an area. The DOJ also wants branches to be in areas with commercial activity, especially small business activity. Moreover, the branches themselves are generally required to be sufficiently involved in commercial activity. The DOJ further encourages the divestiture of branches that are owned, not leased, and branches that have sufficient facilities to adequately serve bank customers.

The Department of Justice is not only concerned with which branches are sold, but with who buys them. The DOJ typically requires that a single firm purchase all divested branches in a market. Because they are especially concerned with the effect of mergers on small business lending, the DOJ prefers that the purchaser be active in commercial lending. In other words, the purchaser must be either a thrift with at least 2 percent of its assets held as commercial loans or a commercial bank. The DOJ further assesses the suitability of a potential buyer by looking at its business plan, product offerings, staffing, and backroom support capabilities. The DOJ also takes into consideration whether the purchaser already has a market presence or whether it would be a new competitor in the market, but the agency's preference depends on the specific issues of the case.

The DOJ has a number of other provisions to its divestiture policy that are intended to enhance the effectiveness of mergers. Among them is the requirement that banks assign each customer to a single branch and then assign all of that customer's accounts to that single office. In this way, all of a customer's accounts are either included in or excluded from a divestiture, making runoff, in their opinion, less likely. The DOJ wants to avoid situations such as a customer having a checking account at a non-divested branch, but a certificate of deposit and a home equity loan at a divested branch. In a situation like this, the customer would hold accounts at two banks and it is believed that the customer would be more apt to consolidate all accounts at one institution. The DOJ requires banks to assign a customer to the branch that is used most frequently (typically the branch that houses the customer's checking account). By doing this, runoff might be kept to a minimum, as the incentive to move accounts out of the divested branch is reduced.

The Federal Reserve Board gets much less involved than the Department of Justice with the specifics of the divestiture process. The Board's primary concern is the size of the divestiture and its effect on the structure of the market. One preference of the Board is that divestiture packages be sold to out-of-market firms because a divestiture 
to a firm without an existing presence results in the number of firms remaining unchanged, which should help maintain the level of competition in the market. Even though the Board requires that a branch and all associated deposits and loans be divested, it is much less involved than the DOJ in dictating to banks how to determine which loans are "associated" with a given branch.

\section{Sample of Divested Branches}

The analysis in this paper examines 751 bank and thrift offices that were divested between June 1989 and June 1999 in conjunction with a merger in the U.S. that raised possible antitrust concerns. The divested offices were identified from a number of sources, including letters from the Department of Justice to bank regulators, Federal Reserve Board Orders, lists of divested branches provided by participating banks, and year-to-year comparisons of the Summary of Deposits (SOD), which reports deposits of all U.S. bank and thrift offices as of June 30th of each year. The sample includes a substantial share of all branches that were divested in the U.S. during the period.

After identifying the divested branches, annual deposit levels for each branch were collected from SOD reports. One year of pre-merger data was collected for each branch from the June immediately preceding consummation of the merger. In calendar time, the pre-merger year ranged from 1989 to 1998 , and in event time, this pre-merger year is referred to as year 0 .

Post-divestiture data were collected for as many years as possible until 2001, the last year for which SOD data were available at the time the dataset was constructed. In about 55 percent of the observations, the first post-divestiture observation is for the year immediately following the pre-merger year. In these cases, both the merger and divestiture were completed between the pre-merger June and the following June.

With the other 45 percent of sample branches, the first post-divestiture observation reflects deposits from two years after the pre-merger observation. In these cases, the merger was completed before the June following the pre-merger year, but divestitures were not completed until after the June SOD was filed. Therefore, the acquirer from the primary merger owned the divested branch in the year immediately following the pre-merger year, and the eventual purchaser 


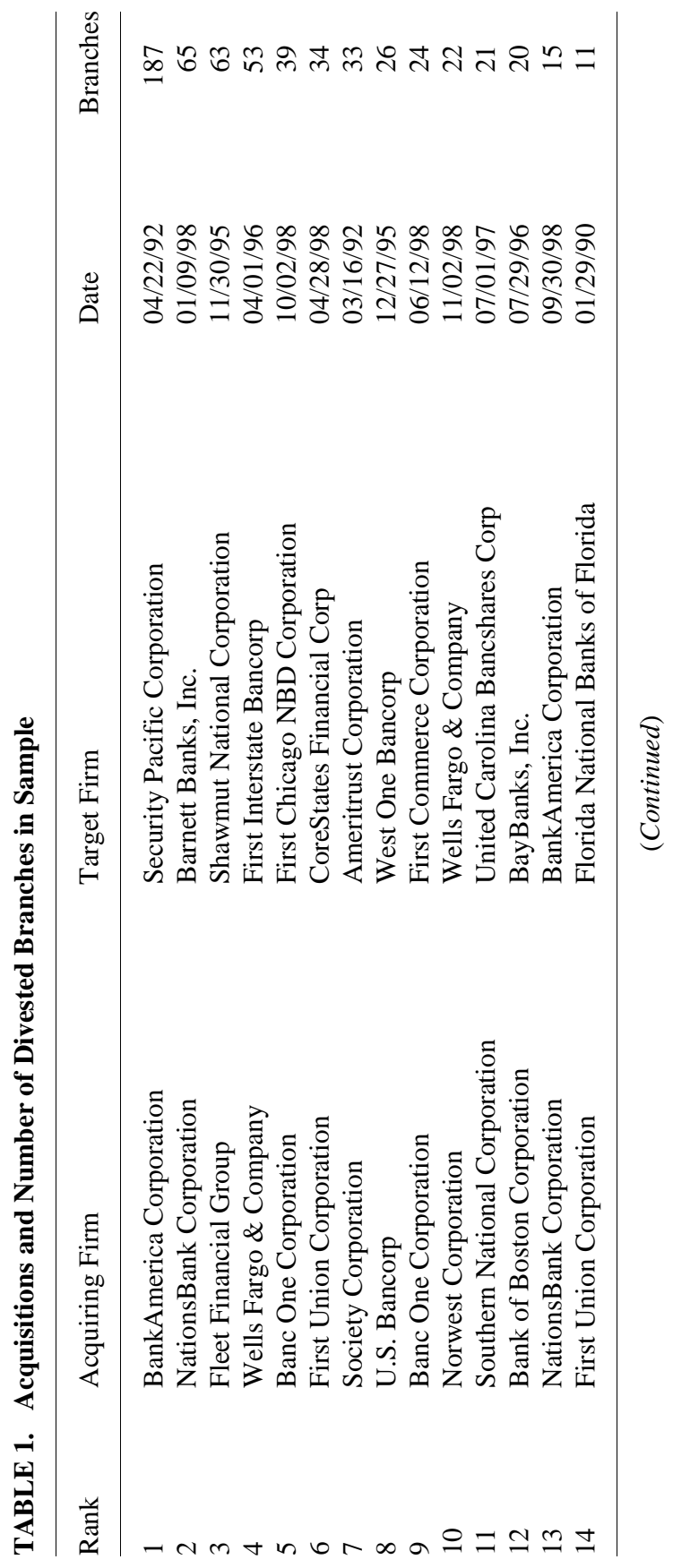




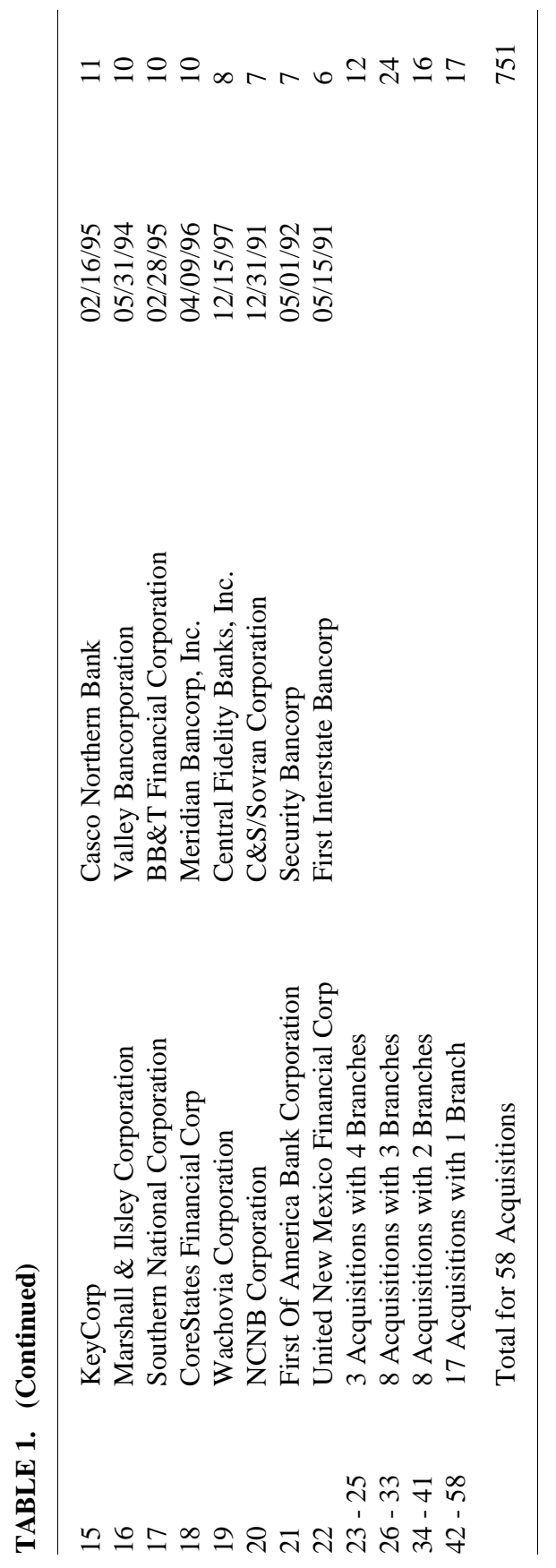


owned the branch by the next year. The first post-divestiture year is referred to as year 1, regardless of whether it is one or two years after the pre-merger year, and subsequent years are referred to as year 2, year 3 , etc.

To be included in the sample, a divested branch must be observable on the pre-merger SOD and the first post-divestiture SOD. Branches that could not be tracked either immediately before or after the merger were excluded. In addition, branches that were divested after the first June following the merger also had to be observable on the post-merger, pre-divestiture SOD. Because all sample divestitures took place by June 1999, there were at least three possible post-divestiture observations for each branch (1999, 2000, and 2001).

Divested branches were tracked over time by matching addresses reported on the SOD. In many cases, however, the reported address associated with a divested branch changed over time, especially at the time of divestiture or some other subsequent merger activity. Lists of divested branches (often with deposits and frequently provided by the Department of Justice), personal judgment, and telephone calls to staff at various branches were used to determine the cause of the change in the reported address. If the different addresses referenced the same facility, then the same branch was considered to have operated during the time period. ${ }^{15}$ However, if the facility was different, even if it was because the bank moved to a larger and better office next door, the office was not considered the same, and the original branch was considered to have stopped operating.

The 751 branches were divested in 219 counties in 37 states in conjunction with 58 different mergers. There was a large range in the number of divested branches that the counties contribute to the sample with many counties contributing few branches and a small number of counties contributing many branches. Approximately 40 percent of the counties contribute only a single divested branch to the sample, and another 20 percent of the counties contribute two branches. In contrast, a few urban counties were home to large divestitures and therefore account for a disproportionate share of the branches in the sample. In five of the counties represented in the sample, at least 20 (but no more

15. A great deal of effort was spent matching the 751 divested branches over time. A few examples of branches with different addresses for the same facility are the following: 2183 Park Avenue is the same office as Park and Milwaukee Avenues, 65 Lake Mead Drive is the same as 65 West Lake Mead Drive, and 2000 Market Street is the same as 20th and Market Streets. 
than 31) branches were divested. There are four different acquisitions represented by these sizable divestitures.

Table 1 presents a list of the acquisitions that contribute the largest number of branches to the sample. Clearly, branches divested by BankAmerica Corporation as part of its acquisition of Security Pacific Corporation in early 1992 account for the largest share of the branches in the sample. Nearly 190 branches, or roughly one-fourth of the sample are associated with this deal. Other deals that contributed a large, albeit much smaller, share of the divested branches include NationsBank-Barnett (65 branches), Fleet-Shawmut (63), and Wells Fargo-First Interstate (53). Most of the deals represented in the sample are associated with only a few divested branches. Roughly 30 percent of the 58 deals contribute a single branch and another 30 percent contribute two or three branches to the sample.

Eighty-six different firms purchased divested branches. Two firms acquired more than 50 of the sample branches, and another two purchased more than 40 offices. Moreover, nine banks and thrifts purchased between 20 and 40 branches. In contrast to these substantial acquisitions of divested branches, there were 28 purchasers that acquired a single office and twelve that purchased two offices.

The mergers that are included in the sample took place roughly over the decade of the 1990s. For about one-third of the sample, the pre-merger observation is as of June 1991. These deals are largely attributable to Bank of America-Security Pacific, but other deals, including Society-Ameritrust, also contributed to the large total. June 1995 and June 1997 are also common pre-merger dates, with slightly more than 20 percent of the sample having each of these as its pre-merger date.

\section{Analysis: Survival Rates}

The first type of analysis conducted in this study is an examination of survival rates, which are defined as the percentage of divested branches that operated for at least a given number of years following divestiture. Panel A of table 2 presents a complete survival rate analysis for the 751 divested branches in the sample. The first column indicates the year of the first post-divestiture SOD for the branches described in each row (except the last two rows). The second column reports the number of branches in the sample that had a given year as their first 


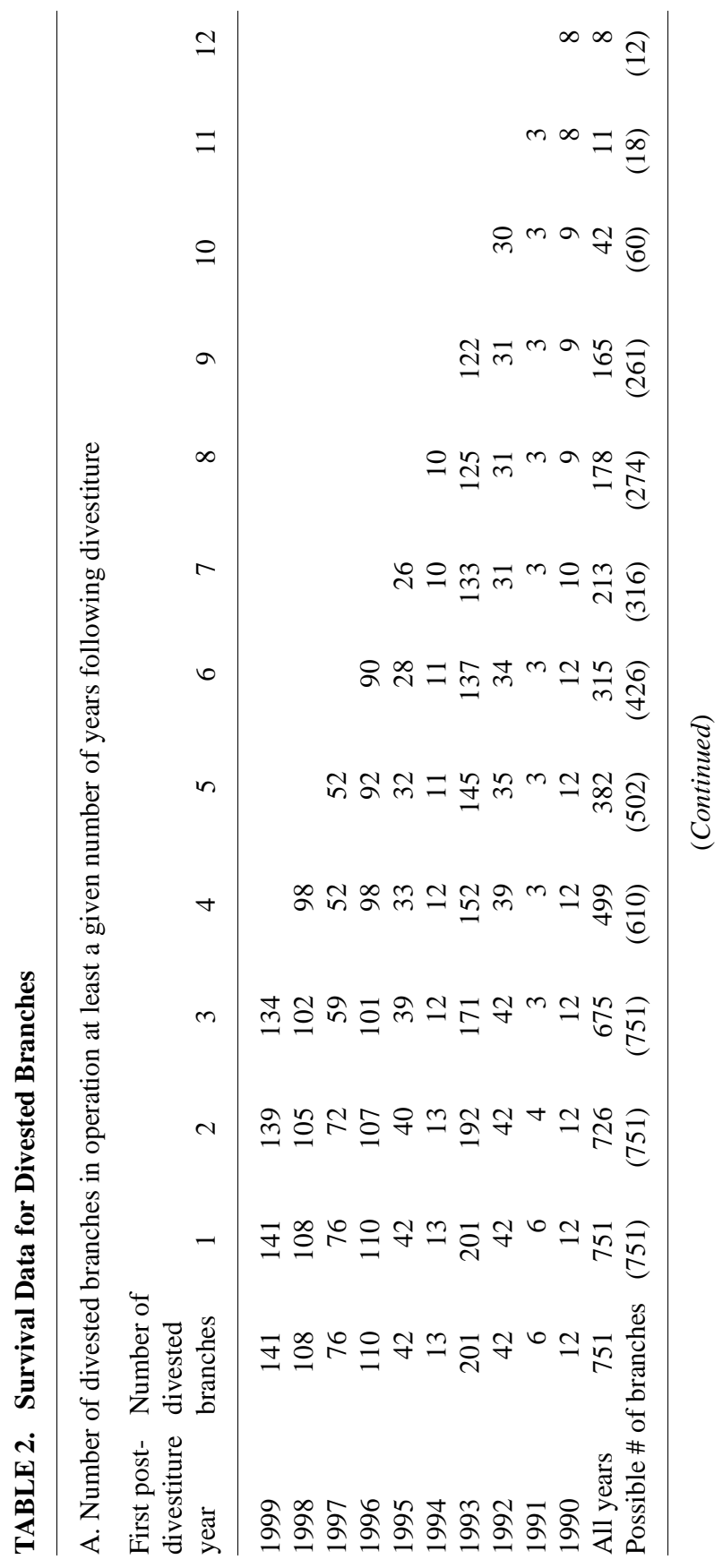




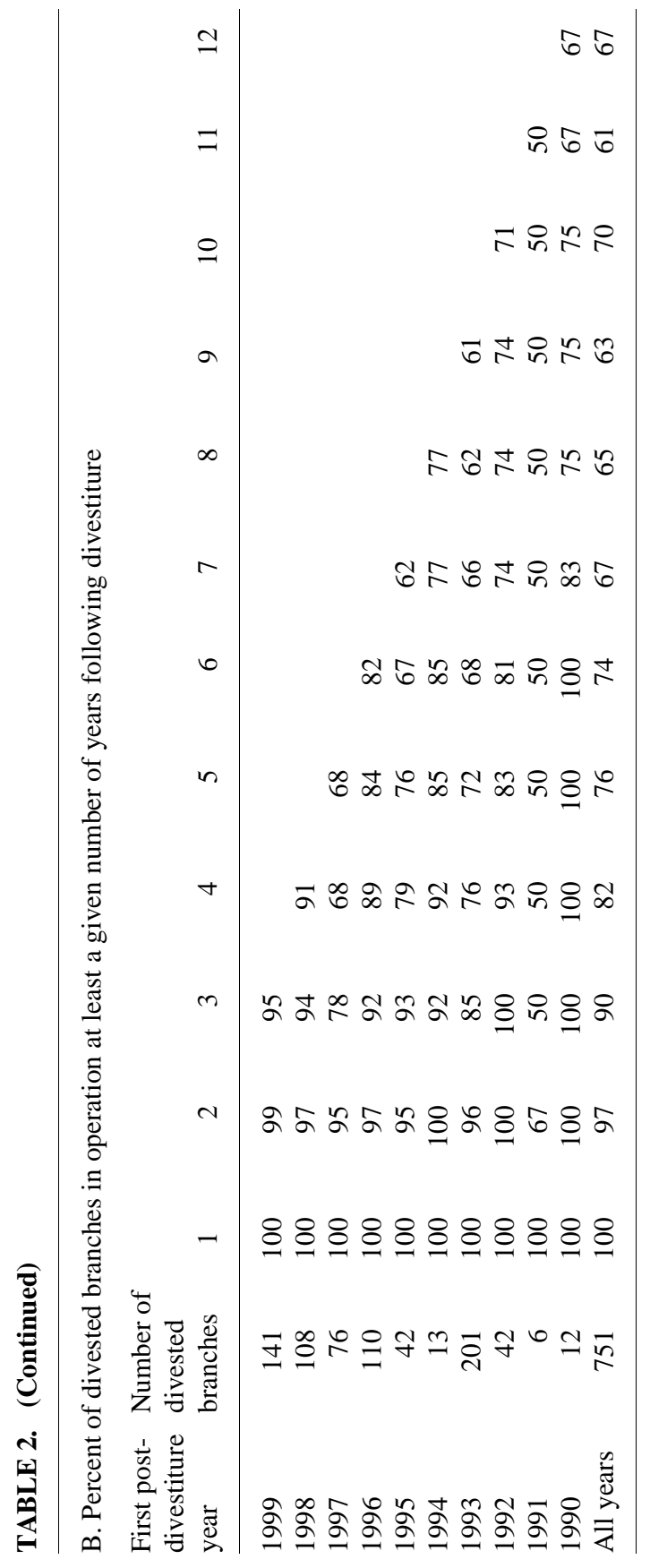


post-divestiture year. Finally, the last twelve columns report how many branches survived at least a given number of years following divestiture. Panel B reports the information as a share of the figure reported in column two.

For example, the second row reports information on the 108 branches that had 1998 as the year of their first post-divestiture SOD. The table indicates that, consistent with sample construction rules, all 108 of the branches were in operation for the first possible post-divestiture year. Three of the branches were not in operation during the second possible post-divestiture year (1999), leaving 105 surviving branches. Panel B indicates that 105 branches correspond to 97 percent of the 108 that could have operated during the second year following divestiture. The table also indicates that 102 branches (94 percent) survived at least to the third year (2000) and 98 branches (91 percent) operated during the fourth and final post-divestiture period (2001).

The second last row of panel A reports the actual number of branches that survived at least the number of years following divestiture indicated by the number in the column heading, and the last row reports the maximum number of branches that could have been observed surviving at least that number of years. The maximum number of years that a branch could have been observed surviving is based solely on the length of time between the first post-divestiture year and 2001, the last year of SOD data, and is independent of the number of years that a particular branch actually survived. Therefore, the number of possible branches that corresponds to each of the figures in the second last row decreases across the table, because the number of branches that could have survived at least a given number of years decreases as that given number of years increases. For example, all 751 branches could have been observed operating during the second post-divestiture year, but only 316 branches could have been observed operating during the seventh year following divestiture. Of the 316 branches, 213 (67 percent) operated during that seventh year.

The figures in table 2 seem to suggest that divested branches were very likely to continue operating from year-to-year. Roughly 97 percent of the divested branches operated at least two post-divestiture years, and year-to-year survival rates were roughly on the order of 90 to 95 percent for subsequent years. However, although the figures on divested branches are interesting, they do not tell us how the survival rates of divested branches compared to other branches. Seeing that divested branches operated for a length of time that is at least comparable to the 
typical branch would be consistent with divestitures having been effective, because it would suggest that divested branches have been able to operate as successfully as other U.S. branches. To address this issue, benchmark figures were constructed.

For each year of data, 1989 to 1998, all branches on the SOD with a reported address were tracked forward by looking at how many consecutive years each address appeared on the SOD. As soon as an address does not exist on the SOD or is associated with zero deposits, the branch was considered to have stopped operating.

In order to maximize the number of accurate matches that could be identified, several steps were taken to make addresses uniform across time including dropping all punctuation and spelling out common words and numbers. Although these steps helped generate between 50,000 and 64,000 matches per two-year period, the efforts were nonetheless somewhat limited in identifying all appropriate branch matches over time. Sometimes, a reported address referencing a particular facility changed, even though the actual physical structure remained the same. ${ }^{16}$

To make the benchmark similar to the sample, every branch in the benchmark group was classified as being in one of the nine U.S. Census divisions and in either a rural or urban area. Urban areas were defined as counties in metropolitan statistical areas using 1999 definitions. Then, survival rates were measured for each of the eighteen division-urban/rural combinations in the same way that they were measured for the 751 divested branches as reported in panel B of table 2. A weighted average of the eighteen sets of survival rates was then taken using the number of divested branches in each division-urban/rural combination as the weight to get the benchmark survival rates. The number of years that took place between pre-merger and post-divestiture was also taken into account with the appropriate weighting. ${ }^{17}$ Benchmark survival rates are presented in table 3 .

16. As discussed earlier, a great deal of effort was spent tracking the 751 divested branches over time. Due to resource limitations, similar care could not be taken with the tens of thousands of benchmark offices.

17. Benchmark survival rates were computed in two ways. First, all branches on the SOD were initially included for each year. Then, only branches that could be tracked during the following year were kept. This condition was comparable to requiring divested branches to be observable before the merger and after the divestiture. This process was repeated for each year, 1989 to 1998. The second approach was to include all branches that could be tracked for three consecutive years. Survival rates between the first and last of these three years were treated as one-year rates to be comparable to those of divested branches that had a two-year gap between the pre-merger SOD and the post-divestiture SOD. 
60

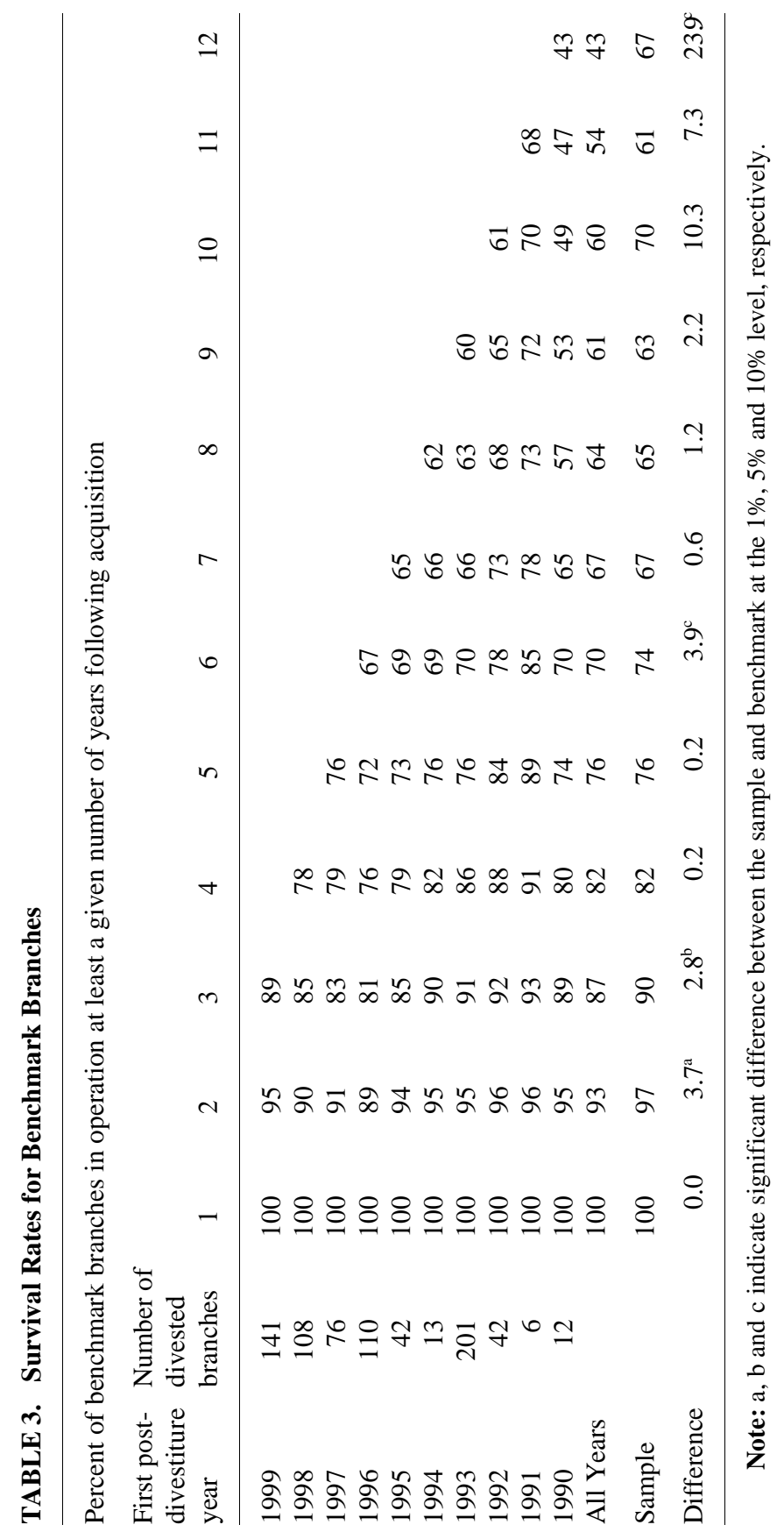


The most relevant comparison is to look at survival rates for all branches that could have survived at least a given number of years following divestiture. The figures for such a comparison are provided in the last several rows of table 3. The table indicates that whereas 97 percent of the sample branches survived at least two post-divestiture years, only 93 percent of the benchmark banks survived a comparable period. The three-year survival rates show a similar pattern, with 90 percent of divested branches surviving versus 87 percent of the benchmark branches.

Although these two differences are statistically significant and suggest that divested branches were more likely to continue operations after two or three years than other comparable branches, it is difficult to draw any strong conclusions. Matching branches over time is a time-consuming process and much more effort was given to matching the 751 divestiture branches than the tens of thousands of benchmark branches. Moreover, the difference between the sample and benchmark survival rates is generally insignificant for post-divestiture periods of time greater than three years. After comparing the magnitude of differences between the sample and benchmark survival rates and taking into account the difficulties with tracking branches with the SOD over time, the data seem to suggest that divested branches tended to operate for roughly as long as other U.S. branches.

An important caveat to the survival analysis is that it takes a narrow view of the operating status of a branch. There are many reasons that a facility might discontinue operating and more than a few of them are not associated with the bank office being unsuccessful. A bank may close an older branch and open a newer, larger one nearby to better serve a growing and profitable customer base. In this case, the old branch would have discontinued operations because it had been "too successful." Another reason that a bank may close a branch is cost reducing consolidation. A bank may wind up with two branches in the same area (often as a result of a merger) and may close one to save on costs. The decision may have nothing to do with the ability of the closed branch to serve its customers. Therefore, it is important to keep in mind that while the survival rate analysis provides us with relevant and interesting information about post-divestiture performance, there are limits in the strength of any conclusions that can be drawn. 


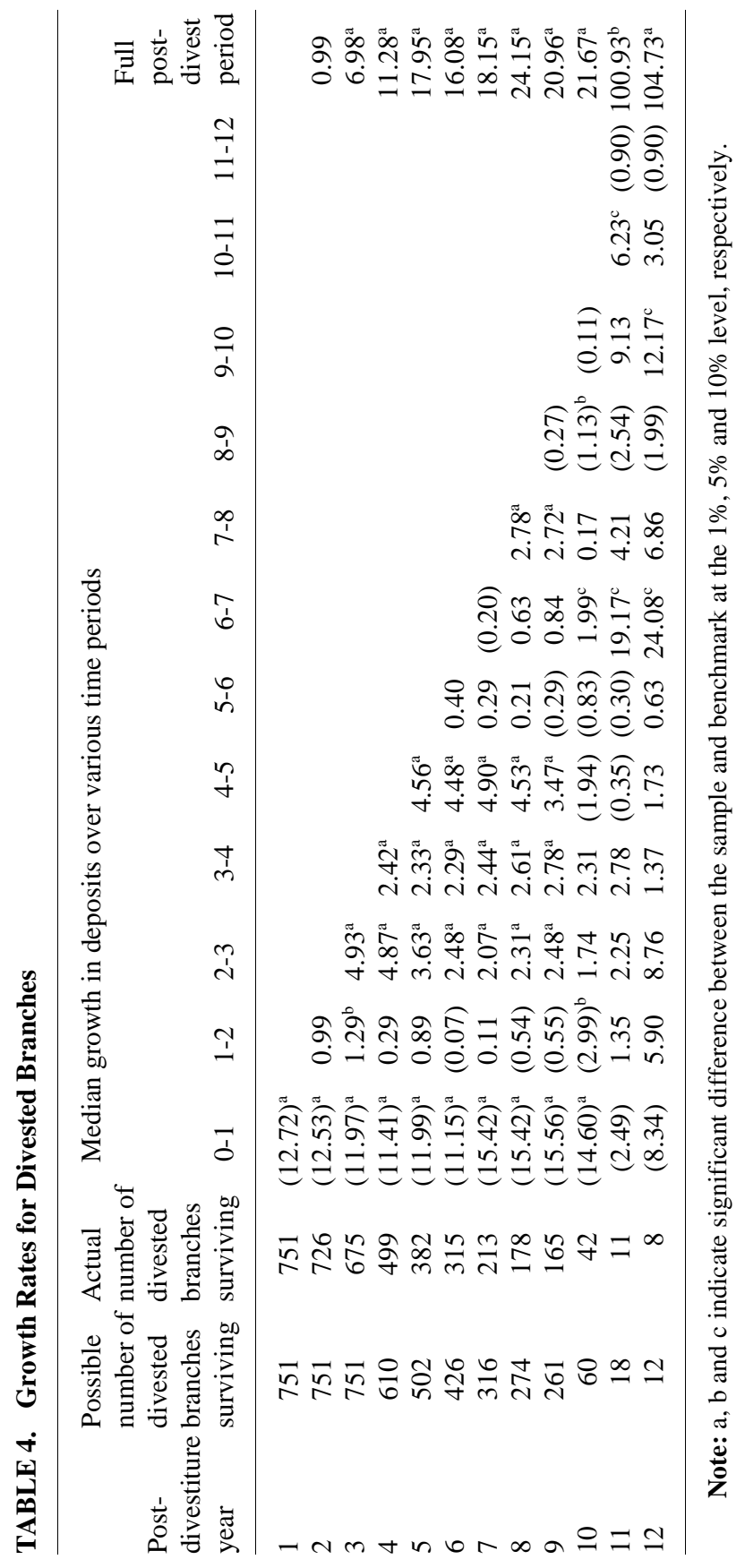




\section{Analysis: Growth Rates}

The second type of analysis is an examination of deposit growth. If a divested branch is able to retain and attract deposits, then it is more likely that customers view it as a viable alternative, and it is more likely that the branch provides meaningful competition. The rate at which a branch is able to grow its deposits provides insight into its ability to meet customer needs.

Growth was measured for various periods for every divested branch in the sample. Median values are reported in table 4 . The second column of the table reports the maximum number of banks that could have survived at least the number of post-divestiture years listed in column one, and the third column lists the number of branches that actually survived that long. The remainder of the columns report the median growth rates over different periods experienced by branches that operated at least as long as the relevant number of post-divestiture years. The last column reports median cumulative growth rates during the post-divestiture period and the preceding columns report one-year growth rates. ${ }^{18}$ For example, the median growth in deposits between the pre-merger year (0) and the first post-divestiture year (1) was -11.97 percent for the 675 branches that operated for at least three post-divestiture years. Following divestiture, the growth rate for these branches between years 1 and 2 was 1.29 percent and the growth rate between years 2 and 3 was 4.93 percent. The median cumulative growth rate during the two-year, post-divestiture period (year 1 to year 3 ) was 6.98 percent.

Median deposit growth rates are better suited than means to measuring the growth of the typical branch, because medians, unlike means, are not heavily influenced by outliers. By definition, positive growth rates are asymmetrically larger in magnitude than negative growth rates. The lowest value that growth can take is -100 percent, whereas the highest value has no upper limit. Therefore, mean growth rates can be heavily influenced by a small number of extremely large values. For instance, there are numerous examples among benchmark branches of year-to-year growth rates exceeding 15,000 percent. These growth rates may represent reporting errors or may be the result of branch consolidation or deposit reallocation. Even if some or all of the

18. In the analysis of growth rates, the post-divestiture period begins with year 1 . Therefore, for example, growth between years 1 and 4 is referred to as the three-year growth rate. 


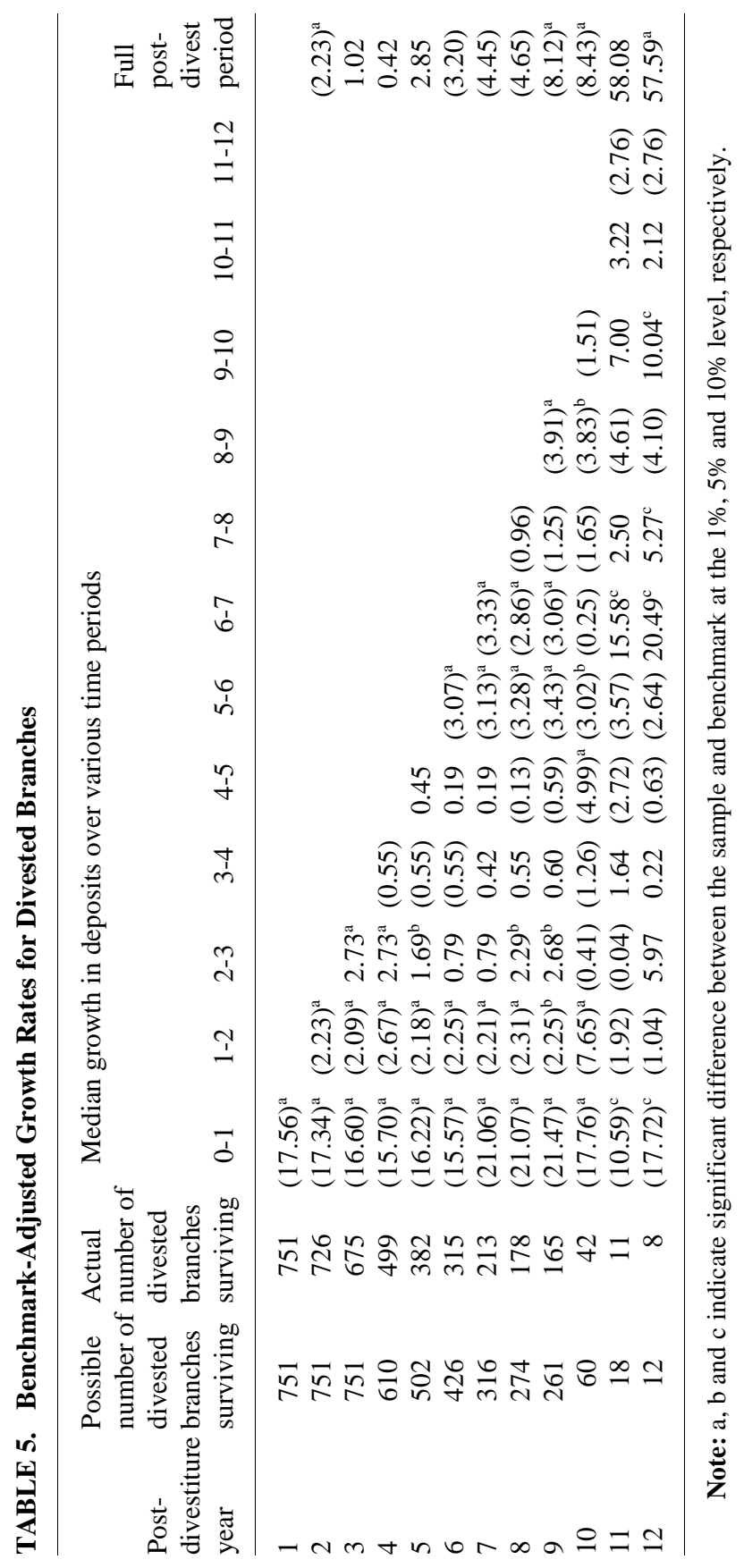


outliers were a result of errors, it would be difficult to know which observations should be dropped and which should be kept. Using medians allows these outliers to be included in the analysis with only a limited influence on reported values. ${ }^{19}$

There is one clear pattern that emerges from table 4: divested branches lose a substantial share of deposits between the pre-merger and post-divestiture SOD reporting dates. About three-quarters of the 751 branches lost deposits between years 0 and 1, with the median change being -12.72 percent. In subsequent years following divestiture, changes tended to be positive and more modest in magnitude. The data suggest that after initially losing a significant share of their deposits, the divested branches were able to reverse that pattern and grow.

Growth rates of divested branches must be examined relative to the growth rates experienced by similar branches. To do this, growth rate benchmarks are created in much the same way as survival rate benchmarks. Growth is measured over one- and multi-year time periods, starting from various points in time, for all branches in the benchmark group. Then, median growth rates are measured for the eighteen groups of branches based on the possible combinations of the nine Census divisions and the urban/rural split. The process is done twice; once with growth between year 0 and year 1 measured over a one-year period and once with growth between year 0 and year 1 measured over a two-year period.

Each of the 751 branches is matched with a relevant benchmark based on the year of the pre-merger SOD, the location of the branch, whether one or two years transpired between the pre-merger and post-divestiture periods, and the number of years that the branch operated. The difference between growth of divested branches and median growth of benchmark branches is computed to get adjusted growth rates. These rates reflect the performance of divested branches relative to similar branches. Median values of benchmark-adjusted growth rates are presented in table 5.

Examining runoff between the pre-merger and post-divestiture period relative to other branches suggests an even larger loss of deposits

19. A simple example that illustrates the effect of the asymmetry on means is a branch that sees its deposits decline from $\$ 5$ million to $\$ 1$ million, and another branch that sees its deposits increase from $\$ 1$ million to $\$ 5$ million. The two growth rates would be -80 percent and 500 percent, respectively, which averages out to 210 percent. The two branches generate a very high average growth even though there is a total of $\$ 6$ million in both branches at both points in time. 
at divested branches. The median difference between growth of the 751 divested branches and growth at other branches was -17.56 percentage points. Because SOD data are reported once a year at a given point in time, it is impossible to tell when the runoff occurred. It is unclear from the data how much of this runoff took place before the merger, how much occurred between the merger and divestiture, and how much took place after divestiture. This information would shed light on the extent to which depositors fled in anticipation of the change in their bank and the extent to which depositors may not have been satisfied with the bank that purchased their branch. Information on what happened to the lost deposits, which would also provide valuable insight into the merger process and its effects on customers and other banks, is also unavailable.

There is no clear pattern in deposit growth for years following the divestiture. Divested branches sometimes grew more rapidly and sometimes grew more slowly than other branches by a modest amount, and at other times they grew at about the same rate as other branches. Relative deposit growth was a statistically significant 2.23 percent below the benchmark between years 1 and 2 among the 726 branches that survived that long. However, it is unclear if this under-performance represents continued, albeit milder, runoff, or if it is simply part of a post-divestiture period during which divested branches did about as well as all branches on average with some yearly fluctuations.

Growth rates between the pre-merger and post-divestiture period presented in table 5 indicate that divested branches retained and attracted significantly fewer deposits than other, similar branches during this time of transition. However, the figures do not indicate how much of this reduction in deposits may be attributable to the disruption and inconvenience associated with the divestiture and how much may be attributable more generally to the merger.

Customers of any branch that undergoes a change in ownership generally experience some disruption or inconvenience in their banking activities because the new bank often institutes different policies and procedures, operates under new rate and fee schedules, and closes offices. Converting accounting, computer, and other systems from those of the former institution to those of the new institution can also introduce a myriad of problems. In addition, during the period immediately preceding the actual sale of their branch, customers may experience a reduced level of service from owners, managers, and employees who may have little incentive to keep customers satisfied. As 
TABLE 6. Growth Rates From Year 0 to Year 1 (in percent)

\begin{tabular}{lccc}
\hline & \multicolumn{2}{c}{$\begin{array}{l}\text { Number of similar non-divested target } \\
\text { branches owned by the acquiring organization } \\
\text { in the first post-divestiture year }\end{array}$} \\
\cline { 2 - 4 } Measure & At least 1 & At least 10 & At least 20 \\
\hline $\begin{array}{l}\text { Median growth in deposits of } \\
\text { divested target branches }\end{array}$ & -11.68 & -12.15 & -13.22 \\
$\begin{array}{l}\text { Median growth in benchmark based on } \\
\text { deposits of non-divested target branches }\end{array}$ & -6.82 & -6.82 & -6.82 \\
$\begin{array}{l}\text { Median growth in benchmark based } \\
\text { on deposits of all branches }\end{array}$ & 4.84 & 4.84 & 4.84 \\
$\begin{array}{l}\text { Median differences } \\
\text { Divested less benchmark based on } \\
\text { all non-divested target branches }\end{array}$ & $-5.08^{\mathrm{a}}$ & $-4.93^{\mathrm{a}}$ & $-4.86^{\mathrm{a}}$ \\
$\begin{array}{l}\text { Divested less benchmark based on } \\
\text { all branches }\end{array}$ & $-16.44^{\mathrm{a}}$ & $-17.08^{\mathrm{a}}$ & $-18.30^{\mathrm{a}}$ \\
$\begin{array}{l}\text { Number of divested target branches in } \\
\text { deals with sufficient number of similar } \\
\text { non-divested target branches }\end{array}$ & & & 480 \\
\hline
\end{tabular}

Note: a indicates significant difference at the 1 percent level. Sign tests are conducted to test for significance..

a result of changes and problems around the time a merger takes place, customers often flee their new bank for one that offers better service, prices, or convenience.

In order to distinguish between the effects of the merger and those of the divestiture on customer runoff, the growth rates of branches that were divested are compared to the growth rates of branches that were acquired in the same merger, but not divested. Specifically, for each divested branch in the sample that belonged to a target firm, the median growth rate between year 0 and year 1 is measured for all other target branches that were acquired, but not divested and that were located in the same census division and urban/rural area type as the divested branch. There were 598 divested branches that could be matched up with at least one other non-divested branch. Table 6 indicates that the median growth rate of these target-owned, divested branches was -11.68 percent between years 0 and 1 . In contrast, the median growth rate of benchmarks based on similar branches that were acquired, but 
not divested, was -6.82 percent. The median growth rate of benchmarks based on all similar branches to those that were divested was 4.84 percent.

These growth rates indicate that the decline in deposits observed during the so-called runoff period can be attributed to both the merger and the divestiture, with the merger accounting for about 70 percent of the difference and the divestiture for about 30 percent. The median growth rate of divested branches was about 16 percentage points less than the growth of all branches: roughly 5 percentage points of this amount are attributable to the difference between branches that were divested and branches that were acquired but not divested, indicating that about 11 percentage points are attributable to the difference in growth rates at branches that were acquired and all branches overall. When the minimum number of branches that must be included in the group of branches that were acquired, but not divested, is raised, the number of divested branches that can be analyzed decreases, but results remain similar.

These findings suggest that the disruption and inconvenience for customers of a particular branch may be greater when the branch is divested as part of a bank merger than when the branch is included in the primary acquisition and not divested. Integrating branches acquired by divestiture may be more difficult than integrating other acquired offices, because such branch sales are less likely to involve executives, managers, and other staff of the acquired bank that may help smooth the transition process. Often, members of an acquired bank's management and staff are retained to assist in both the initial transition and ongoing operation of the consolidated bank. Another possible explanation for why divested branches experience more runoff than other acquired branches is that divested branches may have been selected for sale by the acquiring firm because such branches were more likely to experience substantial runoff. However, it is unclear that runoff can be predicted accurately, and given that the divested branches must be sold to a willing buyer, it is also unclear that purchasers would be willing to repeatedly buy branches that experience large amounts of deposit loss.

Annual growth rates indicate that after experiencing substantial runoff, divested branches grew comparably to other branches in the industry. This pattern suggests that divested branches tended to provide meaningful competition by being able to retain and attract deposits as well as other, similar branches. However, the pattern also suggests that divested branches were significantly smaller after divestiture than 
before. Roughly 70 percent of the size reduction appears to be associated with the branch being involved in an acquisition, and 30 percent appears to be associated with the branch being divested. As a result of the reduction in deposits, pre-merger deposit levels that do not take into account the likely high level of deposit runoff may overstate the influence of divested (and other acquired) branches on post-merger competition. This finding suggests that antitrust authorities and bank regulators may want to further examine the issue of whether to explicitly incorporate the effect of runoff into their competitive analysis of proposed bank mergers.

\section{Conclusion}

Divestitures are a key element of the bank merger policies of antitrust authorities and bank regulators in the U.S. By selling offices in markets that raise concerns about a substantial reduction of competition, acquiring firms can complete deals that otherwise might be considered antitrust violations. However, the question remains as to how effective divestitures are at promoting competition. The analysis in this paper sheds some light on this issue by examining the survival and growth rates experienced by a large sample of branches that were divested between 1989 and 1999.

Survival rate analysis indicates that divested offices are very likely to continue operating from year-to-year. The analysis also indicates that the probability of a divested branch operating for at least a certain number of years after divestiture is comparable to the probability of similar branches operating over the same period of time.

Deposits at divested branches decline substantially during the period from shortly before the merger to shortly after the divestiture. Roughly 70 percent of the runoff that occurs during this time appears to be associated with the branch being acquired as a result of a merger, and about 30 percent is associated with the branch being divested instead of operated by the acquiring firm. Substantial runoff suggests that the influence on the market of divested (and other acquired) branches may be smaller than indicated by pre-merger deposit levels. After the initial decline in deposits, divested branches grow at a comparable rate to other branches, suggesting that they effectively retain and attract customers.

The findings of this paper are consistent with the success of the policy of U.S. antitrust authorities and bank regulators accepting the 
divestiture of bank branches as a remedy for reducing the anticompetitive effect of certain mergers and acquisitions. Divested branches operate for lengths of time that are comparable to all branches, and even though they experience substantial deposit runoff around the time of the merger, divested branches subsequently exhibit deposit growth rates that are comparable to those of other similar branches.

\section{References}

Amel, D. F. and Starr-McCluer, M. 2002. Market definition in banking: Recent evidence. The Antitrust Bulletin 47: 63-89.

Amel, D. F. and Liang, J. N. 1997. Determinants of entry and profits in local banking markets. Review of Industrial Organization 12: 59-78.

Berger, A. N. and Hannan, T. H. 1998. The efficiency cost of market power in the banking industry: A test of the 'quiet life' and related hypotheses. Review of Economics and Statistics 80: 454-465.

Berger, A. N. and Hannan, T. H. 1989. The price-concentration relationship in banking. Review of Economics and Statistics 71: 291-299.

Burke, J. 1998. Divestiture as an antitrust remedy in bank mergers. Finance and Economics Discussion Series working paper no. 1998-14. Washington, DC: Board of Governors of the Federal Reserve System.

Cyrnak, A. W. and Hannan, T. H. 1999. Is the cluster still valid in defining banking markets? Evidence from a new data source. The Antitrust Bulletin 44: 313-331.

Group of Ten. 2001. Report on Consolidation in the Financial Sector.

Hannan, T. H. 1997. Market share inequality, the number of competitors, and the HHI: An examination of bank pricing. Review of Industrial Organization 12: 23-35.

Hannan, T. H. and Prager, R. A. 2004. The competitive implications of multimarket bank branching. Journal of Banking and Finance 28:18891914

Hannan, T. H. and Liang, J. N. 1995. The influence of thrift competition on bank business loan rates. Journal of Financial Services Research 9: 107-122.

Heitfield, E. A. and Prager, R. A. 2004 The geographic scope of retail deposit markets. Journal of Financial Services Research 25:37-55.

Kahn, C.; Pennacchi, G. and Sopranzetti, B. 2000. Bank consolidation and consumer loan interest rates. Proceedings of a Conference, The Changing Financial Industry Structure and Regulation: Bridging States, Countries, and Industries. Chicago, IL: Federal Reserve Bank of Chicago: 536-593.

Kamerschen, D. R. and Frame, W. S. 1997. The profit-structure relationship in legally protected banking markets using efficiency measures. Review of 
Industrial Organization 12: 9-22.

Kramer, II, J. R. and Grace, E. C. 2001. Recent issues concerning divestitures in bank mergers. Handouts. Washington, DC: Seminar sponsored by the Financial Institutions Committee of the Antitrust Section of the American Bar Association (May 9).

Neill, D. S. 2001. A guide to the policies and procedures affecting antitrust divestitures in bank mergers. The Banking Law Journal 118: 603-622.

Pilloff, S. J. 1999. Multimarket Contact in Banking. Review of Industrial Organization 14: 163-182.

Pilloff, S. J. and Rhoades, S. A. 2002. Structure and Profitability in Banking Markets. Review of Industrial Organization 20: 81-98.

Prager, R. A. and Hannan, T. H. 1998. Do substantial horizontal mergers generate significant price effects? Evidence from the banking industry. Journal of Industrial Economics 46: 433-452.

Rhoades, S. A. 1995. Market share inequality, the HHI, and other measures of the firm-composition of a market. Review of Industrial Organization 10: $657-674$.

U.S. General Accountability Office. 2002. Federal Trade Commission: Study Needed to Assess the Effects of Recent Divestitures on Competition in Retail Markets. Report to Congressional requesters. 